\title{
O trabalho do coordenador na Hora de Trabalho Pedagógico Coletivo (HTPC): um olhar para a formação docente em serviço
}

DOl: http://dx.doi.org/10.21165/el.v50i1.2863

\section{Neuraci Rocha Vidal Amorim \\ Lília Santos Abreu-Tardelli²}

\section{Resumo}

Este artigo objetiva apresentar a síntese da análise de três textos sobre o trabalho do coordenador pedagógico: a lei municipal que regulamenta a função da Hora de Trabalho Pedagógico (HTPC), um diário de campo de uma professora-pesquisadora no momento da HTPC e um comentário escrito pela coordenadora e que compõe o método de instrução ao sósia. As análises foram feitas com base no folhado textual do interacionismo sociodiscursivo (BRONCKART 1999, 2006, 2008; MACHADO; BRONCKART, 2009) e complementado pela teoria polifônica da enunciação de Ducrot (1984). Nosso objetivo com as análises é discutir a formação docente a partir da investigação do trabalho do coordenador pedagógico e do espaço da HTPC. Os resultados apontam a falta de autonomia do coordenador na HTPC e a amputação de suas decisões em relação à formação continuada dos professores.

Palavras-chave: Hora de Trabalho Pedagógico Coletivo; trabalho do coordenador; formação de docentes em serviço.

1 Professora Municipal de Educação Básica I, Votuporanga, São Paulo, Brasil; neuramorim@gmail.com; https://orcid.org/0000-0003-1719-2435

2 Universidade Estadual Paulista "Júlio de Mesquita Filho", São José do Rio Preto, São Paulo, Brasil; lilia.abreu-tardelli@unesp.br; https://orcid.org/0000-0001-7870-1710 


\title{
The pedagogical coordinator's work during the Collective Pedagogical Work Hour. a look at in-service teacher education
}

\begin{abstract}
This articleaims to present the synthesis of the analysis of three texts about the pedagogical coordinator's work: the municipal law that regulates the Collective Pedagogical Working Hour (HTPC), a field diary kept by the teacher-researcher during the HTPC moments, and a commentary written by the coordinator which compounds the "instruction to the double" method. The analyses were conducted within the Sociodiscursive Interactionism's (ISD) text framework (BRONCKART 1999, 2006, 2008; MACHADO; BRONCKART, 2009) and complemented by Ducrot's polyphonic enunciation theory (1984). Our objective with the analyses is to discuss teachers' education based on the research about the pedagogical coordinator's work and the HTPC's space. The results point to the coordinator's lack of autonomy at the HTPC and the amputation of their decisions regarding teachers' continuing education.
\end{abstract}

Keywords: Collective Pedagogical Work Hour; coordinator's work; in-service teacher education.

\section{Introdução}

Este artigo $^{3}$ se insere no escopo de pesquisas que investigam o trabalho educacional a partir da análise das ações e discursos no e sobre o trabalho, ou seja, nas diferentes situações de trabalho (reuniões de professores, sala de aula, reuniões pedagógicas etc.) e em textos sobre o trabalho educacional (leis e textos prescritivos de modo geral) ${ }^{4}$.

Ao reconhecer a pertinência da abordagem do trabalho do professor, Machado (2004) adota aportes teóricos das ciências do trabalho, mais especificamente da Ergonomia da Atividade francesa e da Clínica da Atividade, unindo-os aos aportes do interacionismo sociodiscursivo para investigar textos elaborados em situação de trabalho docente e sobre esse trabalho, a fim de compreender como esse ofício é configurado verbalmente por meio de prescrições, avaliações, interpretações 5 .

3 Este artigo é um recorte da dissertação de mestrado de Amorim (2017).

4 Uma síntese da gênese dessa compreensão é materializada na obra de 2004, 0 ensino como trabalho: uma abordagem discursiva, organizada por Anna Rachel Machado, para defender a investigação do trabalho educacional a partir de diferentes coerções: do sistema educacional, dos sistemas de ensino, dos sistemas didáticos, dos artefatos materiais ou simbólicos, dos impedimentos e conflitos internos ou externos.

5 Todos os aportes teórico-metodológicos citados têm como base a compreensão vigotskiana do desenvolvimento humano. 
Este artigo investiga uma das dimensões do trabalho docente que é a participação em reuniões pedagógicas que, dentre outras finalidades, se volta para a formação continuada de professores em serviço. Devido ao fato de essa tarefa do professor estar diretamente ligada ao coordenador pedagógico, responsável por esse momento, discutimos a formação docente a partir da investigação do trabalho desse profissional. Como afirma Machado (2010, p. 164): "o trabalho do professor é constituído de múltiplas atividades desenvolvidas em diferentes situações, que precisam ser investigadas, e interrelacionadas".

Uma dessas situações é o momento de formação continuada que ocorre durante a Hora de Trabalho Pedagógico Coletivo ${ }^{6}$ (HTPC), e que fica a cargo de um profissional legalmente instituído, o coordenador pedagógico. A HTPC, de acordo com a Legislação7, deve fomentar na escola a formação do professor em serviço e o fortalecimento do grupo de docentes, priorizando uma aprendizagem que possibilite o desenvolvimento adequado aos discentes. Nesse espaço, o coordenador pedagógico é o responsável por garantir a efetivação do que orientam as prescrições. A HTPC torna-se, então, objeto de investigações por diferentes pesquisadores cuja finalidade é caracterizar, discutir os problemas pela ótica docente e analisar a influência desse momento para o trabalho dos professores. É o caso dos estudos de Bozzini e Oliveira (2006), Oliveira (2006), Mendes (2008), Fogaça (2010), França e Marques (2012), Souza (2013), Bozzini e Freitas (2014) e De Grande (2015). Além desses trabalhos, encontramos também pesquisas que buscam compreender o processo de formação de professores a partir da perspectiva do trabalho do coordenador pedagógico, pois é o responsável por mediar as reflexões dos professores acerca de suas práticas. Dessa forma, os estudos de Machado e Arribas (2011), Fernandes (2012), Cunha, Ometto e Prado (2013), Mansano (2014), Placco, Souza e Almeida (2012) discutem o papel do coordenador na busca por garantir que a formação continuada possa ocorrer nas escolas.

Machado e Arribas (2011) discutem a necessidade de o coordenador ter garantidos os meios adequados para cumprir os papéis de formador e pesquisador no espaço escolar. Fernandes (2012), após discutir as publicações da Secretaria de Estado da Educação de São Paulo, nos anos de 1996 a 2010 para buscar o entendimento do trabalho do coordenador pedagógico, considera que essa função está alterada devido ao grande número de tarefas e à regulação do docente.

6 De acordo com Bozzini e Freitas (2014), no ano de 2012, a denominação de Hora de Trabalho Pedagógico Coletivo (HTPC), na rede estadual de ensino, foi alterada para Atividade de Trabalho Pedagógico Coletivo (ATPC). Neste artigo, empregamos Hora de Trabalho Pedagógico Coletiva (HTPC) devido à denominação que consta na legislação do município onde os dados foram coletados.

7 Lei complementar n² 215/12 do município onde se situa a escola onde os dados foram coletados. 
Este artigo vem fazer coro às vozes dos demais trabalhos sobre o coordenador pedagógico e sobre a importância do espaço da HTPC na formação docente. Para atingirmos nosso objetivo, iniciamos apresentando o quadro epistemológico do interacionismo sociodiscursivo (doravante ISD), que prioriza a importância das práticas de linguagem como instrumentos do desenvolvimento humano, em seguida, a metodologia e o resultado das análises realizadas e, por fim, as considerações finais para que possamos compreender as funções de fato exercidas pelo coordenador na HTPC e como isso pode (des)orientar a formação do professor em serviço que dela participa.

\section{0 quadro de análise textual na perspectiva do ISD}

O Interacionismo Sociodiscursivo (ISD) é uma abordagem que compreende as práticas linguageiras como instrumentos do desenvolvimento humano (BRONCKART, 2006). Relacionada a essa importância das práticas linguageiras, para o ISD, a ação, na perspectiva psicológica, é acessível somente de modo indireto, sendo sua interpretação possibilitada por uma metodologia desenvolvida com base em Ricoeur, vinculada aos textos elaborados antes, durante ou depois dela (MACHADO; FERREIRA; LOUSADA, 2011).

Assim, para a construção dessa metodologia interpretativa, Bronckart (1999) elabora o quadro de análise textual posteriormente reorganizado e complementado (BRONCKART; MACHADO, 2004; MACHADO; BRONCKART, 2009, BRONCKART, 2006, 2008). O quadro de análise possibilita "detectar essas representações ou(re) configurações) com um instrumental analítico bastante refinado e informado pelos estudos da linguagem" (MACHADO; FERREIRA; LOUSADA, 2011, p. 19).

Em sua proposta de análise, Bronckart (1999) compreende que a estruturação de um texto é composta por três camadas interativas e interligadas hierarquicamente, a exemplo de um folhado textual: a infraestrutura geral do texto, os mecanismos de textualização e os mecanismos enunciativos.

A infraestrutura geral do texto, segundo o autor (1999), apresenta: o plano mais geral do texto, os tipos de discurso e as sequências. Os mecanismos de textualização, segunda camada, são responsáveis pela conexão, coesão nominal e coesão verbal e, por fim, na terceira camada, os mecanismos enunciativos são compreendidos como o posicionamento enunciativo, as vozes e as modalizações.

Neste artigo, utilizamos principalmente o instrumental analítico conforme apresentado por Machado e Bronckart (2009) por incluir o nível semântico ou referente à semiologia do agir que possibilita a análise de textos sobre o trabalho educativo, no entanto, também recorremos ao texto de Bronckart $(1999,2008)$ e de Bulea (2010). 
O início da análise do texto ocorre, segundo Machado e Bronckart (2009), a partir da exploração do contexto de produção ${ }^{8}$. O contexto de produção designa os parâmetros que influenciam a construção e organização de um texto. Assim, o contexto de produção pode ser subdividido em contexto físico (lugar de produção, tempo físico de produção, identificação do emissor e do receptor) e em contexto sociossubjetivo (normas, regras, valores, a relação sociointeracional entre enunciador e enunciatário). Após o levantamento de hipóteses sobre o contexto de produção, é preciso considerar que o contexto sóciohistórico mais amplo possibilita identificar de que forma os fatores sociais, históricos, culturais e políticos podem ou não ter influenciado as interpretações configuradas nas produções verbais, no nosso caso, sobre o trabalho do coordenador.

Após as considerações sobre o contexto de produção e do contexto sociointeracional mais amplo, ocorre a análise do que se compreende como o nível organizacional do texto. A delineação do plano global, de acordo com os autores, orienta-se a partir de "diferentes índices linguísticos (os macroorganizadores textuais, por exemplo), peritextuais (intertítulos, mudanças de partes ou de capítulos), contextuais (presença de parágrafo introdutório, apresentando as divisões do texto)" (MACHADO; BRONCKART, 2009, p. 54) além dos conhecimentos referentes ao gênero do texto.

Em relação aos tipos de discurso (ainda pertencente à infraestrutura geral do texto), Bronckart (2008) esclarece que todo texto é constituído por partes que podem ser reconhecidas pelo seu papel semântico-pragmático. Cada parte dessa possui um rearranjo de unidades linguísticas próprias, como os tempos verbais, pronomes, conectores, advérbios de modalização. O autor, dessa forma, denomina esses segmentos de tipos de discurso e divide-os em quatro tipos.

O discurso interativo caracteriza-se por constituir-se pelo mundo discursivo conjunto (mundo do expor) à elaboração do texto. Evidencia os parâmetros da situação de produção (implicação) (MACHADO, 1998). Suas propriedades linguísticas caracterizadoras são o emprego de verbos e de pronomes em $1^{a}$ pessoa e de $2^{a}$ pessoa. Presente, futuro perifrástico, imperativo e futuro do presente são os tempos verbais predominantes (MACHADO, 2005).

No discurso teórico, o mundo discursivo é conjunto (mundo do expor) e estrutura o conteúdo "como se sua validade fosse absoluta ou pelo menos como se sua validade

8 Neste artigo, discutimos, de forma sucinta, os elementos textuais que são analisados pelo instrumental do ISD, no entanto, alguns pontos não são discutidos, pois não recorremos a eles para análise de nossos dados neste artigo. Para uma compreensão mais profunda da base epistemológica de Bronckart e dos teóricos de linguagem que compõem sua obra, consultar Atividade de linguagem, textos e discursos: por um interacionismo sociodiscursivo (BRONCKART, 1999). 
fosse independente das circunstâncias particulares do ato de produção" (autônomo) (BRONCKART, 1999, p. 301). Suas características linguísticas são: presente histórico, participantes, tempo e lugar não marcados no texto.

O relato interativo constitui o mundo discursivo do narrar que se encontra disjunto ao do texto. Explicita os parâmetros da situação de produção (implicação) e suas propriedades linguísticas são verbos e pronomes na $1^{\text {a }}$ pessoa e tempos verbais como pretérito perfeito e imperfeito (MACHADO, 1998).

Já o tipo de discurso narração caracteriza-se por constituir-se disjunto do momento de interação e não fazer referências aos parâmetros da produção do texto (autônomo). Prevalece o uso do pretérito perfeito (MACHADO, 1998).

Em relação ao nível enunciativo, identificam-se os elementos que evidenciam a enunciação: primeira ou terceira pessoa, quais as vozes trazidas e quais modalizadores são textualizados. Em relação às vozes, para Machado e Bronckart (2009), quando as inserções de vozes ocorrem de forma explícita (discursos direto e indireto, para $X$, consoante a $X$, aspas, expressões populares), podem evidenciar posicionamentos diferentes a respeito de um mesmo agir dentro do texto. Ainda, a partir do verbo empregado para marcar o início da fala alheia, podemos conhecer a perspectiva do autor do texto. Quando as inserções de vozes são implícitas, para Machado e Bronckart (2009) é preciso recorrer a Ducrot (1987) cuja discussão sobre polifonia difere locutor e enunciador. O estudioso esclarece que:

[...] o sentido do enunciado, na representação que ele dá da enunciação, pode fazer surgir aí vozes que não são as de um locutor. Chamo "enunciadores" estes seres que são considerados como se expressando através da enunciação, sem que para tanto se lhe atribuam palavras precisas; se eles "falam" é somente no sentido em que a enunciação é vista como expressando seu ponto de vista, sua posição, sua atitude, mas não no sentido material do termo, suas palavras. (DUCROT, 1987, p. 192).

Desse modo, o locutor consegue articular e organizar, por meio da enunciação, enunciadores com perspectivas e atitudes diferentes das do locutor. É o caso da conjunção adversativa mas e da negação que fazem surgir dois enunciadores (DUCROT, 1987).

Em relação às modalizações, parte integrante dos mecanismos enunciativos (terceira camada do folhado textual), segundo Bronckart (1999), as deônticas evidenciam julgamentos sobre o conteúdo abordado sob o ponto de vista das avaliações e regras do mundo social, então expressam perspectivas a partir "do domínio do direito, da obrigação 
social e/ou da conformidade com as normas em uso". Já as modalizações apreciativas, ligadas ao mundo subjetivo, analisam os conteúdos tratados como sendo "benéficos, infelizes, estranhos, etc., do ponto de vista da entidade avaliadora" (BRONCKART, 1999, p. 331-332). Por fim, as modalizações pragmáticas evidenciam "aspectos da responsabilidade de uma entidade constitutiva do conteúdo temático (personagem, grupo, instituição, etc.), em relação às ações de que é o agente, e atribuem a esse agente intenções, razões (causas, restrições, etc.), ou ainda capacidades de ação" (BRONCKART, 1999, p. 332).

De acordo com Machado e Bronckart (2009), no nível semântico, último nível de análise do texto (ampliou-se assim o quadro proposto em 1999), compreendemos as categorias do agir que são subsidiadas pelos níveis: organizacional e enunciativo. Para discussão desse nível, recorremos à Bulea (2010), pois a fim de interpretar o trabalho de enfermeiras, juntamente com essas trabalhadoras, a pesquisadora criou categorias de análises denominadas de figuras de ação. Bronckart e Leurquin (2010) explicam que essas figuras são instrumentos interpretativos advindos da intersecção de escolhas para apresentar o conteúdo e uma determinada mobilização dos recursos da língua.

Assim, a partir da análise das prescrições sobre o trabalho de enfermeiras, Bulea (2010) denominou a ação padrão e, a partir de análises de entrevistas com essas profissionais, identificou as seguintes figuras interpretativas da ação: canônica, experiência, acontecimento passado, definição e ocorrência.

A figura canônica pode ser compreendida como uma interpretação que "propõe uma lógica da tarefa que se apresenta como a-contextualizada, com validade geral e emanando de uma instância normativa exterior ao actante". Nesse caso, o trabalhador apenas cumpre as regras. Quanto à organização discursiva, predomina o discurso teórico ou misto teórico-interativo (BULEA, 2010).

A figura experiência "[...] trata-se primeiramente de constituintes estáveis, incontornáveis, de muito forte recorrência; trata-se, em seguida, de características próprias ao actante, de suas maneiras de fazer [...]" (BULEA, 2010, p. 138). Estrutura-se discursivamente pelo discurso interativo e apresenta advérbios de tempo (normalmente, sempre, muitas vezes) e/ou sintagmas preposicionais e nominais como (de qualquer jeito, todo o tempo).

A figura acontecimento passado "[...] tem claramente um valor ilustrativo do agir em questão ou de uma de suas dimensões, esse valor lhe é conferido pelo caráter não habitual ou propriamente circunstancial de seu conteúdo [...]" que relata fatos inesperados durante o desenvolvimento da tarefa (BULEA, 2010, p. 132). Ocorre por meio de segmentos de relato interativo. 
A figura definição "depende de uma compreensão do agir-referente como objeto de reflexão, ou enquanto ele constitui, ao mesmo tempo, o suporte e o alvo de uma (re) definição por parte do actante" (BULEA, 2010, p. 144). Ocorre a presença predominante dos discursos: teórico ou misto teórico-interativo. Por fim, a figura ocorrência é uma avaliação do agir em que se destacam a contextualização, recorrendo a fatores do entorno do profissional. A organização discursiva dessa figura é marcada pelo discurso interativo (BULEA, 2010).

Após essa breve apresentação do nosso suporte teórico-metodológico, cabe ressaltar que a interligação entre os níveis de análise, para compreensão dos textos sobre o trabalho do coordenador pedagógico, foi importante para caracterizar a formação docente em serviço na escola onde desenvolvemos a pesquisa.

\section{Metodologia do levantamento e da análise do corpus}

O estudo foi realizado em uma unidade escolar de Ensino Fundamental Anos Iniciais ( $7^{\circ}$ ao $5^{\circ}$ ano) de uma rede de ensino de um município do noroeste paulista. Duas coordenadoras são as participantes da pesquisa: a que coordenou a escola no ano de 2015, mas que ao término do referido ano, por questões particulares, retornou à sala de aula em outra unidade e a coordenadora que posteriormente assumiu a coordenação. Uma professora-pesquisadora (a autora da dissertação de mestrado) também é uma das participantes.

Os dados ${ }^{9}$ desta pesquisa são: (i) documentos que prescrevem a coordenação pedagógica no município pesquisado (Seção IV da Lei Complementar n 215, de 05 de julho de 2012), (ii) um diário de campo redigido pela professora-pesquisadora e o (iii) comentário oriundo do método de instrução ao sósia. Faremos uma breve síntese da escolha desses textos para análise e o que foi analisado em cada um.

Em relação ao primeiro dado, que serviu para compreender a interpretação do trabalho do coordenador pedagógico que está presente nas prescrições sobre a coordenação pedagógica, foi obtido na legislação referente à HTPC, Lei Complementar n² 215, de 05 de julho de 2012 do município onde realizamos este estudo. Esse dispositivo "Dispõe sobre o Estatuto e Plano de Carreira e Remuneração do Magistério Público do Município de XXX e dá outras providências correlatas" (lei do município, 2012). Como não existe outro texto que prescreve a HTPC, desse material, selecionamos a Seção IV do Capítulo IV, pois é essa parte que se refere ao trabalho do coordenador. Esse texto, que compõe o corpus, foi analisado por meio da organização temática conforme propõem Machado e Bronckart (2009).

9 Salientamos que foram respeitados os procedimentos éticos estabelecidos pelo Comitê de Ética em pesquisa que permitiu a realização em janeiro/2016 (registro: CAAE: 49887115.2.0000.5466). 
O segundo dado são os diários de campo que possibilitam identificar a interpretação da professora-pesquisadora sobre a formação de professores que ocorre na HTPC. Sobre esses textos, Rocha e Eckert (2008) explicam que, depois de deixar o contexto de pesquisa, é importante redigir os diários. Neste artigo, os materiais analisados foram elaborados depois das reuniões de HTPC. Desse modo, em 2015 e no primeiro trimestre letivo de 2016, foram escritos vinte e dois diários de campo. O processo metodológico da escolha dos diários a serem analisados partiu do critério temático em que o trabalho do coordenador foi o tema central. Dessa forma, motivados pelo objetivo de compreender o trabalho do coordenador, focamos nos quatorze em que encontramos avaliações sobre as coordenadoras. Um outro recorte desse material foi a escolha pelo diário da HTPC do dia 28/07/2015 por ser representativo dos comentários sobre o trabalho da coordenadora contidos nos demais diários de campo. Nesse texto, investigamos as vozes e seus gerenciamentos enunciativos, de acordo com Bronckart (1999), Machado e Bronckart (2009), Ducrot (1987), e as modalizações conforme Bronckart (1999).

O terceiro dado é o comentário produzido pela coordenadora responsável pela HTPC no ano de 2016. Esse comentário escrito compõe uma das fases do método de instrução ao sósia ${ }^{10}$ que utilizamos a fim de que a coordenadora pudesse interpretar seu agir, podendo vislumbrar suas ações no trabalho de um modo talvez desconhecido para ela mesma. Em relação à escrita do comentário, "é o processo narrativo [...] que é considerado como produtor de sentido e como tendo um estatuto verdadeiramente desenvolvimental" [...] (BULEA, 2010, p. 33). Para a análise textual desse comentário, discutimos o contexto de produção, problematizamos os tipos de discursos, conforme Bronckart (1999), Machado (1998) e Machado (2005), e identificamos as figuras de ação de acordo com Bulea (2010).

A seguir, são apresentadas as sínteses das análises realizadas e as discussões oriundas delas.

\section{Prescrições: o coordenador é responsável pela formação continuada na escola?}

O plano global das prescrições sobre o trabalho do coordenador (especificamente, a Seção IV da Lei Complementar n² 215, de 05 de julho de 2012) revelou que, dos nove temas presentes na Seção IV, quatro deles se referem à HTPC, indicando que há, tematicamente, uma predominância na delimitação desse espaço de trabalho coletivo. Mais especificamente no quinto tema do plano global ("estabelecimento das prioridades

10 Em linhas gerais, esse método se assemelha a uma entrevista semiestruturada. Segundo Clot (2006a), foi desenvolvido por Oddone (1981), sendo constituído pelas seguintes etapas: fornecimento ao sósia (pesquisador ou psicólogo do trabalho que realiza o método) de relato minucioso sobre a tarefa selecionada, escuta da gravação do relato fornecido ao sósia, transcrição, composição do comentário escrito pelo trabalhador e posterior discussão com os demais profissionais do grupo. 
ao planejar, organizar e conduzir a HTPC"), há a indicação de algumas ações, tais como: considerar a demanda dos professores em relação às metas e prioridades da escola, elaborar pauta, dividir as tarefas relativas à reunião e buscar maneiras de avaliar a reunião. Tais ações indicam maior interação e envolvimento dos professores no momento da formação, interação que não ocorrerá, pois, como veremos mais à frente, na análise do diário de campo, as pautas e o material já vêm prontos da secretaria municipal da educação.

A releitura dos conteúdos temáticos listados no plano global em relação aos termos de registros do agir possibilita-nos ver a predominância de menções a um agir-situadodecorrente: "as horas de trabalho pedagógico coletivo - HTPC deverão ser planejadas e organizadas pelo Assessor de Coordenadoria Pedagógica de cada segmento da Educação Básica" (Lei do Município, 2012). No entanto, no que diz respeito aos protagonistas colocados em cena na lei, não há ocorrência do coordenador exercendo a função sintática de sujeito, havendo apenas seres inanimados ocupando a posição de protagonistas do agir.

Há um grande predomínio da modalização deôntica expressa pelo verbo dever, remetendo às esferas das normas e prescrições. Se em um primeiro olhar, a modalização deôntica possa parecer a "esperada" para este gênero de texto, em uma análise atenta, verifica-se que em um documento que visa à prefiguração do agir do coordenador, a ausência do coordenador como protagonista desse agir não deve passar despercebida.

Na síntese da análise do diário de campo, que segue, veremos que essa constatação da amputação de possibilidades do agir do coordenador na HTPC vai ao encontro do que é relatado pela professora-pesquisadora, autora do diário.

\section{Diário de campo: a formação de professores em um momento difuso}

A análise do diário de campo, escrito pela professora-pesquisadora em um momento posterior à HTPC e tendo dela participado, foi realizada principalmente em relação ao nível organizacional do folhado textual, mais especificamente, aos tipos de discurso e, em relação aos mecanismos enunciativos, às vozes e às modalizações.

Os tipos de discursos identificados no diário de campo foram o discurso teórico (predominantemente) e mesclas desse com o discurso interativo. A presença do discurso teórico em um gênero diarista, revelando a ausência de implicação com o conteúdo do plano global, coloca o texto do diário em uma posição de independência em relação ao momento de produção, e pode ser interpretado como o que está sendo dito ser um fato recorrente e não específico daquele dia e momento de observação. O trecho abaixo é um exemplo da predominância do discurso teórico (não há marca de pessoa do discurso, nem elementos que situam o momento de interação): 
1. Há um excesso de informalidade que por um lado é positivo, mas por outro extremamente negativo. Todo mundo se sente muito à vontade para falar de assuntos que muitas vezes não estão relacionados com o assunto discutido (DC1) ${ }^{11}$.

Em relação aos mecanismos enunciativos, mais especificamente a análise das vozes no texto, a voz da coordenadora apresenta-se de modo indireto pelas expressões: "na fala dela" e "de acordo com ela". Essas fórmulas demonstram que a instância de enunciação traz a fala da coordenadora a fim de garantir a fonte da insatisfação em relação às orientações fornecidas pela secretaria municipal de educação, conforme o exemplo seguinte:

2. Algumas vezes ficou evidente na fala dela insatisfação com as orientações recebidas pela secretaria, descrédito, pois, de acordo com ela, em alguns momentos a orientação é uma depois a orientação é outra (DC1).

No diário de campo, a polifonia no nível do enunciado materializada pela conjunção adversativa mas traz à tona duas concepções diferentes sobre o agir da coordenadora. O excerto abaixo apresenta que o Enunciador 1 considera positivo a coordenadora dar atenção às falas dos docentes e se solidarizar com os problemas, já o Enunciador 2 julga que gera uma gama de assuntos que impedem, na HTPC, uma discussão com base em teorias.

3. A coordenadora tem paciência para ouvir os relatos, sempre demonstra compreender as angústias (E1), mas ficamos sempre numa profusão de assuntos que impossibilita uma reflexão mais profunda, com embasamento científico (E2) (DC1).

Dessa forma, as vozes gerenciadas pela instância enunciativa caracterizam a HTPC como um momento difuso devido aos variados temas que surgem e, sobre a coordenadora, há referências à inexistência de uma concepção desse momento de formação em serviço. Em contrapartida, a voz dessa profissional, trazida ao texto pela professora-pesquisadora, denuncia a imprecisão das orientações recebidas para realizar seu trabalho.

A análise das modalizações evidencia pouco envolvimento em relação ao que é afırmado, pois os modalizadores indicam que as vozes buscam ser imparciais na compreensão do trabalho de coordenação:

4. Pelo jeito existe muita cobrança por parte da secretaria e pouco respaldo para as coordenadoras. As prescrições recebidas por elas não parecem ser claras (DC1).

11 Diário de campo redigido após a HTPC do ano de 2015. 
Assim, o trabalho da coordenadora configurado no diário de campo no momento da HTPC aponta um cenário de formação difuso, pouco definido e pouco aproveitado.

\section{Comentário escrito pela coordenadora: uma reflexão sobre o trabalho}

O terceiro dado deste trabalho é o comentário escrito pela coordenadora. O levantamento do contexto de produção (aspectos físicos e sociosubjetivos) nos permite levantar as hipóteses de que o texto foi escrito na residência da coordenadora para a pesquisadoraprofessora. Esse comentário faz parte do método de instrução ao sósia e a escrita dele foi motivada por uma sucinta orientação enviada, pela pesquisadora, através de e-mail pessoal. A elaboração desse texto ocorreu depois da entrevista de instrução ao sósia ${ }^{12}$ realizada no dia 28/03/2020.

A partir desse contexto, a coordenadora, responsável pela realização da HTPC, comenta a entrevista, discutindo questões relacionadas à realização de seu trabalho na coordenação.

Apesar de, em um primeiro momento, termos a hipótese de que o destinatário do texto é a pesquisadora, alguns excertos indicam o desejo da coordenadora de ampliar o alcance dessa interação. A exemplo disso, podemos citar a parte em que a coordenadora defende a importância de a diretora permanecer na unidade escolar nos dias em que ocorre a HTPC. No trecho abaixo, um dos outros ${ }^{13}$ destinatários é explicitamente nomeado:

5. Isso vai soar como um desabafo, mas gostaria que todos entendessem, inclusive a própria $S M E$, que não é possível ao coordenador desdobrar-se em várias pessoas ao mesmo tempo. (C2)

A respeito das figuras de ação mobilizadas pela coordenadora para interpretar seu trabalho durante a HTPC, foram identificadas a canônica, a experiência, a acontecimento passado e a definição. Seguem exemplos de cada uma dessas figuras de ação demonstrando que a coordenadora construiu um processo interpretativo do trabalho desenvolvido por ela em HTPC por meio de perspectivas diferentes.

12 A entrevista de instrução ao sósia é um dos métodos indiretos propostos pela Clínica da Atividade para a concretização de um trabalho clínico de fortalecimento do trabalhador em seu ambiente de trabalho. Para maior detalhe sobre os métodos indiretos, vide Clot (2006).

13 Para uma discussão aprofundada sobre o papel do outrem no trabalho, conferir a tese de Hernandes-Lima (2020). 
6. Gosto de fazer a pauta dos assuntos para minha própria organização, para não correr o risco de esquecer algo e, também, para registro, visto que muitas vezes recebemos visita dos assessores da Secretaria de Educação, que acompanham os HTPC e gostam de levar uma cópia do que foi trabalhado. (Figura de ação experiência)

7. A coordenadora relata um estado inicial: "o texto daquela semana foi enviado no dia anterior". Uma complicação ou uma controvérsia: "um texto longo com uma linguagem não tão fácil". "Não foi possível a leitura do texto na escola". Um ato ou uma série de atos visando à resolução: "pedi ajuda a outra coordenadora para compartilhar o Power Point que havia montado". A resolução efetiva: "A decisão de não iniciar pelo texto de reflexão". Uma avaliação ou uma repreensão: "senti que falhei em alguns pontos. O maior deles foi não ter trabalhado com o texto previsto para aquele HTPC". (Figura de ação acontecimento passado)

8. Acho que é um momento rico, pois podemos compartilhar saberes, pensar em soluções, pensarmos como grupo, como equipe. Sei que às vezes é cansativo, mas se soubermos aproveitar, pode se transformar em um momento gostoso para trocar informações. Para a coordenadora, é o momento de ver sua equipe. (Figura de ação definição).

9. [...] o HTPC é função do Coordenador da escola, faz parte das atribuições o seu preparo e realização, sendo também parte das obrigações do professor. Por isso, o HTPC deve ocorrer. (Figura de ação canônica).

Desse modo, compreendemos que a coordenadora recorre a diferentes instrumentos para se voltar ao seu fazer profissional: há momentos em que mobiliza uma visão lógica (ação canônica), em outros a experiência acumulada (ação experiência) também ilustra a situação vivida (ação acontecimento passado) e ainda apresenta definições para sua tarefa (ação definição).

Essas diferentes figuras interpretativas, portanto, podem indicar que a escrita do comentário possibilitou à coordenadora um espaço de reflexão, sob diferentes prismas, sobre o trabalho que realiza durante a HTPC.

\section{Considerações finais}

A síntese aqui apresentada das análises efetuadas do corpus deste trabalho (seção VI da legislação do município, um diário de campo escrito pela professora-pesquisadora e o comentário elaborado pela coordenadora), sob a perspectiva teórico-metodológica do ISD, permite-nos afirmar que o trabalho do coordenador no contexto pesquisado é envolvido por contradições. Apontaremos duas delas a fim de direcionarmos nossas reflexões para possíveis ações numa formação docente no espaço da HTPC.

A primeira contradição diz respeito à prescrição da HTPC pela legislação. O levantamento do plano global da legislação municipal que prescreve a HTPC possibilitou identificar que o trabalho de coordenar inclui o planejamento, a organização e a condução desse 
espaço de formação docente em serviço, apesar de o coordenador não ser posto como protagonista do agir nesse contexto de formação. Porém, a análise do diário de campo da professora-pesquisadora e do comentário elaborado pela coordenadora indicam que as coordenadoras e os docentes apenas realizam o que é anteriormente definido por outros agentes que não lidam diretamente com as questões do cotidiano deles. Esse fato se contrapõe com o que estabelecem as prescrições da legislação do município e compromete diretamente a autonomia da coordenação, pois o planejamento e a organização da HTPC, que deveriam ser de responsabilidade do coordenador, são realizados por outros profissionais, pertencentes à instância superior, da secretaria municipal da educação e, portanto, não cientes dos problemas locais da escola em que professor e coordenador atuam.

A segunda contradição é em relação ao trabalho da coordenação. As figuras de ação definição e figura de ação experiência, mobilizadas pela coordenadora no comentário escrito, indicam que o trabalho da coordenação é possibilitar o estudo coletivo, seguindo a pauta determinada pela secretaria municipal de educação, trocar conhecimentos, chegar a resoluções conjuntas para as dificuldades, ter contato com a equipe e abordar assuntos relevantes para a unidade escolar. Esse trabalho, no entanto, não se efetua dessa forma, pois, segundo os resultados da análise do comentário, a coordenadora define que o trabalho dela é respeitar o assunto estipulado pela secretaria municipal, fato esse que não está contemplado no documento prescritivo.

Quando nos situamos em um quadro teórico que visa a compreender o trabalho dos agentes da educação, especificamente, do professor e, no nosso caso específico, do coordenador no espaço da HTPC, evidenciar as contradições, dilemas e conflitos em textos produzidos por esses trabalhadores em situação real de trabalho é crucial para podermos identificar os pontos essenciais para que os profissionais possam, em seu coletivo de trabalho, vislumbrar mudanças concretas na situação de trabalho, possibilitando, dessa forma, que as ações desses profissionais não sejam amputadas, preservando, assim sua saúde física e mental ${ }^{14}$.

A ausência de autonomia do coordenador para planejar a HTPC e a pauta imposta pela secretaria da educação para a realização das HTPC dificultam o diálogo entre coordenação e professores assim como entre os próprios professores. Um caminho possível seria abrir espaço para que a pauta da HTPC seja criada pela coordenação, respaldada pelo próprio entendimento da lei sobre a HTPC. Urge que os professores possam usufruir o momento de formação em serviço como um momento coletivo de trocas que possam ir ao encontro de seus problemas, indagações, necessidades formativas, dentre outras demandas apresentadas por eles.

14 Nosso quadro teórico-metodológico, como já dito no início deste artigo, dialoga com a Psicologia do trabalho, mais especificamente com a Clínica da Atividade e com a Ergonomia do Trabalho de linha francesa. 


\section{REFERÊNCIAS}

AMORIM, N. R. V. Coordenação pedagógica duranteaHTPC:as interpretações do coordenador, da professora-pesquisadora e das prescrições. 2017. Dissertação (Mestrado em Estudos Linguísticos) - Instituto de Biociências, Letras e Ciências Exatas, Universidade Estadual Paulista "Júlio de Mesquita Filho", São José do Rio Preto, 2017.

BOZZINI, I. C. T.; FREITAS, D. O trabalho coletivo na escola pública: três estudos sobre o HTPC/ATPC. Interciência \& Sociedade, São Carlos, v. 3, n. 2, p. 60-71, 2014.

BOZZINI, I. C. T.; OLIVEIRA, M. R. G de. Os professores e a construção do espaço coletivo escolar: o horário de trabalho pedagógico coletivo (HTPC). Revista LOGOS, Rio de Janeiro, v. 14, n. 14, p. 36-46, 2006.

BRONCKART, J. P.; LEURQUIN, E. V. L. F. Prefácio. In: BULEA. E. Linguagem e efeitos desenvolvimentais da interpretação da atividade. Tradução Eulália Vera Lúcia Fraga Leurquin e Lena Lúcia Espíndola Rodrigues Figueirêdo. Campinas: Mercado de Letras, 2010. p. 9-22.

BRONCKART, J. P. O agir nos discursos: das concepções teóricas às concepções dos trabalhadores. Tradução Anna Rachel Machado e Maria de Lourdes Meirelles Matencio. Campinas: Mercado de Letras, 2018.

BRONCKART, J. P. Atividade de linguagem, discurso e desenvolvimento humano. Tradução Anna Rachel Machado e Maria de Lourdes Meirelles Matencio et al. Campinas: Mercado de Letras, 2006.

BRONCKART, J. P.; MACHADO, A. R. Procedimentos de análise de textos sobre o trabalho educacional. In: MACHADO, A. R. (org.). O ensino como trabalho: uma abordagem discursiva. Londrina: EDUEL, 2004.

BRONCKART, J. P. Atividade de linguagem, textos e discursos: por um interacionismo sociodiscursivo. Tradução Anna Rachel Machado e Péricles Cunha. São Paulo: EDUC, 1999.

BULEA, E. Linguagem e efeitos desenvolvimentais da interpretação da atividade. Tradução Eulália Vera Lúcia Fraga Leurquin e Lena Lúcia Espíndola Rodrigues Figueirêdo. Campinas: Mercado de Letras, 2010.

CLOT, Y. A função psicológica do trabalho. Tradução Adail Sobral. Petrópolis: Vozes, 2006. 
CUNHA, R. C. O. B.; OMETTO, C. B. de C. N.; PRADO, G do V. T. Trabalho docente coletivo e coordenação pedagógica: entre a heterogeneidade do cotidiano e um projeto de formação de professores. Revista educação, Campinas, v. 18, n. 2, p. 171-179, mai./ago. 2013.

DE GRANDE, P. B. Formação continuada no local de trabalho do professor: possibilidades de agência e construção de sentidos para a docência. 2015. Tese (Doutorado em Linguística) - Instituto de Estudos da Linguagem, Universidade Estadual de Campinas, Campinas, 2015.

DIOLINA, K. Quem ensina, aprende a vencer os desafios da profissão: o papel do coletivo. 2016. Tese (Doutorado em Linguística Aplicada e Estudos da Linguagem) - Pontifícia Universidade Católica de São Paulo, São Paulo, 2016.

DUCROT, O. O dizer e o dito. Campinas: Pontes, 1987.

FERNANDES, M. J. da S. O professor coordenador pedagógico nas escolas estaduais paulistas: da articulação pedagógica ao gerenciamento das reformas educacionais. Educação e pesquisa, v. 38, n. 4, p. 799-814, 2012.

FOGAÇA. F. C. Reuniões pedagógicas e autoconfrontações: possíveis espaços de desenvolvimento profissional na escola pública. 2010. Dissertação (Mestrado em Estudos da Linguagem) - Centro de Letras e Ciências Humanas, Universidade Estadual de Londrina, Londrina, 2010.

FRANÇA, V. D. C.; MARQUES, M. A. de R. B. A relação teoria e prática no espaço das HTPCs: possibilidades de formação continuada da docência centrada na escola. Plures Humanidades, v. 13, n. 2, p. 275-290, jul./dez. 2012.

MACHADO, A. R. Ensino de gêneros textuais para o desenvolvimento do professor e de seu trabalho. In: SERRANI, S. (org.). Letramento, discurso e trabalho docente. Vinhedo: Horizonte, 2010. p.160-171.

MACHADO, A. R. Colaboração e crítica: possíveis ações do linguista na atividade educacional. In: MACHADO, A. R.; ABREU-TARDELLI, L. S.; CRISTÓVÃO, V. L. L. (org.). O ensino e a aprendizagem de gêneros textuais. Campinas: Mercado de Letras, 2009. p. 43-70.

MACHADO, A. R. A perspectiva interacionista sociodiscursiva de Bronckart. In: MEURER, J. L.; BONINI, A.; MOTTA-ROTH, D. (org.). Gêneros: teorias, métodos, debates. São Paulo: Parábola, 2005. p. 237-259. 
MACHADO, A. R. (org.). O ensino como trabalho: uma abordagem discursiva. Londrina: Eduel, 2004.

MACHADO, A. R. O diário de leituras: a introdução de um novo instrumento na escola. São Paulo: Martins Fontes, 1998.

MACHADO, A. R.;BRONCKART, J.P. (Re-)configuração do trabalho do professor construídas nos e pelos textos: a perspectiva metodológica do grupo ALTER-LAEL. In: MACHADO, A. R.; ABREU-TARDELLI, L. S.; CRISTÓVÃO, V. L. L. (org.). Linguagem e educação: o trabalho do professor em uma nova perspectiva. Campinas: Mercado de Letras, 2009. p. 31-77.

MACHADO, A. R.; FERREIRA, A. D'O.; LOUSADA, E. G. Breve definição dos fundamentos e procedimentos dos estudos do professor. In: MACHADO, A. R.; FERREIRA, A. D'O.; LOUSADA, E. G. (org.). O professor e seu trabalho: a linguagem revelando práticas docentes. Campinas: Mercado de Letras, 2011. p. 15-31.

MACHADO, L. B.; ARRIBAS, N. C. A. L de. Coordenador pedagógico na escola pública: uma análise à luz das representações sociais. Educação em foco, v. 16, n. 1, p. 171-192, 2011.

MANSANO, M. S. Dilemas no cotidiano do orientador pedagógico: entre a confrontação com a profissão e a (auto)confrontação docente. 2014. Dissertação (Mestrado em Educação) Centro de Educação e Ciências Humanas, Universidade Federal de São Carlos, Sorocaba, 2014.

MENDES, C. C. T. HTPC: Hora de trabalho perdido coletivamente? 2008. Dissertação (Mestrado em Educação) - Faculdade de Ciências e Tecnologia, Universidade Estadual Paulista "Júlio de Mesquita Filho", Presidente Prudente, 2008.

MUNICÍPIO. Lei Complementar n² 215, de 05 de julho de 2012. Município, 2012.

OLIVEIRA, A. R. de. A HTPC como espaço de formação: uma possibilidade. 2006. Dissertação (Mestrado em Linguística Aplicada e Estudos da Linguagem) - Pontifícia Universidade Católica de São Paulo, São Paulo, 2006.

PLACCO, V. M. N. de S.; SOUZA, V. L. T. de. ALMEIDA, L. R de. O coordenador pedagógico: aportes à proposição de políticas públicas. Cadernos de pesquisa, v. 42, n. 147, p. 754-771, 2012. 
ROCHA, A. L. C da; ECKERT, C. Etnografia: saberes e práticas. In: PINTO, C. R. J.; GUAZZELLIB, C. A. B. (org.). Ciências humanas: pesquisa e método. Porto Alegre: UFRGS, 2008. p. 9-24.

SANTADE, M. S. B. A metodologia de pesquisa: instrumentais e modos de abordagem. In: SIMÕES, D.; GARCIA, F. (org.). A pesquisa científica como linguagem e práxis. Rio de Janeiro: Dialogarts, 2014. p. 97-111.

SOUZA, G. R de. Horas de trabalho pedagógico coletivo (HTPCs): espaço de formação contínua e de produção de saberes docentes. 2013. Dissertação (Mestrado em Educação) - Faculdade de Ciências e Tecnologia, Universidade Estadual Paulista "Júlio de Mesquita Filho", Presidente Prudente, 2013. 